\title{
PCOS AND UTERINE ABNORMALITY; POSSIBLE CONNECTION AND RELATIONSHIP WITH MATERNAL SERUM AMH LEVELS
}

\author{
Gurkan Uncu ${ }^{1}$, Kiper Aslan ${ }^{2}$, Ozge Albayrak ${ }^{3}$, Aylin Orhaner ${ }^{1}$, and Isil Kasapoglu ${ }^{3}$ \\ ${ }^{1}$ Uludag University School of Medicine \\ ${ }^{2}$ Affiliation not available \\ ${ }^{3}$ Uludag University Faculty of Medicine
}

June 8, 2020

\begin{abstract}
Objective: To determine the incidence of uterine abnormalities in patients with PCOS Design: Retrospective Cohort Study Setting: Tertiary University Hospital Population: Infertile patients with PCOS vs. male factor infertility were selected from the IVF center electronic database from between the years 2011-2019. Methods: A total of 103 patients, 51 PCOS, and 52 male factor infertility were enrolled in the study. Hysterosalpingography (HSG) images of all patients were numbered. For the study, six different shapes of the intrauterine cavity were figured. All HSG images were evaluated by ten senior reproductive endocrinologists and surgeons. Seniors were blinded to the research and chose the most appropriate figure for each patient's HSG image. Results and Demographic parameters were compared between PCOS and Male Factor Groups. Anti-Mullerian hormone correlation with Uterine abnormality was further analyzed. Main Outcome Measure: Percentage of the abnormal uterine cavity Results: The percentage of the normal uterine cavity was significantly lower in the PCOS group. $(45.9 \%$ and $73.1 \%, \mathrm{p}<0.01)$ The abnormal cavities were compared; Arcuate Uterus (22.18\% vs $6.6 \% \mathrm{p}<0.05)$, Partial Septate Uterus $(5.1 \%$ vs $0 \% \mathrm{p}<0.05)$, Complete Septate Uterus $(5.47 \%$ vs $1.2 \% \mathrm{p}<0.01)$ and Y-Shaped Uterus $(7.47 \%$ vs $0 \mathrm{p}<0.05)$ were significantly higher in PCOS patients. T-Shaped Uterus (13.8\% vs. $18.9 \%$ ) was statically similar. There was no correlation between serum AMH levels and the presence of uterine abnormality. Conclusion: This study provides that, compared to the healthy population, the uterine abnormality frequency is clearly higher Key Words: Polycystic Ovary Syndrome, Uterine Abnormality, Anti-Mullerian Hormone

PCOS AND UTERINE ABNORMALITY; POSSIBLE CONNECTION AND RELATIONSHIP WITH MATERNAL SERUM AMH LEVELS
\end{abstract}

Gurkan Uncu, Prof. ${ }^{1}$ guncu@gurkanuncu.org

Kiper Aslan M.D. ${ }^{1}$ kiperaslan@yahoo.com.tr

Ozge Albayrak M.D. ${ }^{1}$ drozgealbayrak@gmail.com

Aylin Dayan M.D. ${ }^{1}$ aylindayan@gmail.com

Isil Kasapoglu Assoc. Prof. ${ }^{1}$ kasapogluisil@hotmail.com

Affiliation:

Bursa Uludag University School of Medicine, Department of Obstetrics \& Gynecology

Corresponding Author:

Kiper ASLAN, MD 
Bursa Uludag University, School of Medicine, Department of Obstetrics \& Gynecology

Bursa, Turkey.

Mobile: +905548127272

E-mail: kiperaslan@yahoo.com.tr

Running Title:

Polycystic Ovary Syndrome and Uterine Abnormality

\section{Objective:}

To determine the incidence of uterine abnormalities in patients with polycystic ovarian syndrome

\section{Design:}

Retrospective Cohort Study

\section{Setting:}

Tertiary University Hospital

\section{Population:}

Infertile patients with PCOS vs. male factor infertility were selected from the IVF center electronic database from between the years 2011-2019.

\section{Methods:}

A total of 103 patients, 51 PCOS, and 52 male factor infertility were enrolled in the study. Hysterosalpingography (HSG) images of all patients were numbered. For the study, six different shapes of the intrauterine cavity were figured. All HSG images were evaluated by ten senior reproductive endocrinologists and surgeons. Seniors were blinded to the research and chose the most appropriate figure for each patient's HSG image. The consensus rate was used to determine the normality of the HSG image. Results and Demographic parameters were compared between PCOS and Male Factor Groups. Anti-Mullerian hormone correlation with Uterine abnormality was further analyzed.

\section{Main Outcome Measure:}

Percentage of abnormal uterine cavity

\section{Results:}

The percentage of the normal uterine cavity was significantly lower in the PCOS group. (45.9\% and $73.1 \%$, $\mathrm{p}<0.01)$ The abnormal cavities were compared; Arcuate Uterus (22.18\% vs $6.6 \% \mathrm{p}<0.05)$, Partial Septate Uterus $(5.1 \%$ vs $0 \% \mathrm{p}<0.05)$, Complete Septate Uterus $(5.47 \%$ vs $1.2 \% \mathrm{p}<0.01)$ and Y-Shaped Uterus $(7.47 \%$ vs $0 \mathrm{p}<0.05)$ were significantly higher in PCOS patients. T-Shaped Uterus $(13.8 \%$ vs. $18.9 \%)$ was statically similar. There was no correlation between serum AMH levels and the presence of uterine abnormality.

\section{Conclusion:}

This study provides that, compared to the healthy population, the uterine abnormality frequency is clearly higher in patients with polycystic ovarian syndrome.

\section{Funding:}

None.

Keywords: polycystic ovarian syndrome, anti-mullerian hormone, uterine abnormality, infertility, hysterosalpingography, anovulation, hyperandrogenism

\section{INTRODUCTION}


The complex topic of female genital tract is fascinating. The estimated prevalence of Mullerian abnormalities is approximately $5 \%$, from mild to severe, in the general population and increases up to $13 \%$ in women with infertility.(1) After the classification reported by ASRM in 1988, de nuova abnormalities were reported and recently and in 2013 European Society of Human Reproduction \& Embryology - European Society of Gynecological Endoscopy (ESGE - ESHRE) announced a new classification in terms of uterine abnormalities. (2)

In the classification made by ESGE - ESHRE in 2013, dysmorphic uterus was defined as; a - T shape, b - Infantile, c- Others and no sub -group explanation for the group classified as the others. In the ASRM classification, T shape uterine cavity is classified as class VII. There is no detailed definition of Y shaped cavity and others in the classifications designed by ESGE - ESHRE and ASRM. (2,3) (Figure 1)

Polycystic Ovarian Syndrome (PCOS) is the most common and studied endocrine disorder of fertile-aged women, affecting approximately 5-10\% of the population. PCOS is characterized by several clinical phenotypic presentations, including metabolic and reproductive issues, mainly hyperandrogenemia, elevated serum anti-mullerian hormone (AMH) levels, presence of oligomenorrhea / amenorrhea and insulin resistance.(4)

The higher frequency of pregnancy complications, mainly preterm birth, in PCOS patients than normoovulatory patients has been under discussion for many years.(5-7) The data in the literature regarding the increased preterm birth in PCOS pregnancies and our observations with intrauterine cavity abnormalities in PCOS patients encouraged us to design this research.

The hypothesis of our study is that "the incidence of uterine abnormalities, mainly Y shaped uterine cavity, in PCOS patients is higher than in normo-ovulatory patients and this can be related to maternal serum AMH levels".

\section{METHODS;}

This study is a retrospective cohort analysis which was performed in Bursa Uludag University Faculty of Medicine, Department of Obstetrics and Gynecology, Assisted Reproductive Technologies (ART) Unit.

\section{Patients:}

Fifty-five PCOS and 52 male infertility patients as control group performed ART were included in the study. Patients were retrospectively screened for HSG. HSG images were numerated for each patient. The numbering of HSG images of patients and filing was done by an independent person blind to the research.

For the study, 6 shapes of intrauterine cavity were figured, in accordance with the definitions in the ESGE - ESHRE classification. (Figure1)

Figure I uterine cavity is accepted as normal in both classifications.

Figure II uterine cavity is class VI in the ASRM classification and not classified as an abnormality in the ESGE - ESHRE classification and is considered a variance of the normal, formerly named as arcuate uterine cavity.

Figures III, IV and V uterine cavities are Va, Vb and VII numbered in ASRM classification, and U2a, U2b and U1a in ESGE - ESHRE classification, respectively.

Figure VI uterine cavity is Y-shaped uterus, which has been frequently spoken in recent years but doesn't have any place in classifications. This definition is not included in ASRM and it can be put in the class named U1c in ESGE - ESHRE classification.

All patients included in the study had unicorpus detected by ultrasonographic evaluation.

\section{HSG evaluation:}

Two copies of HSG images of 51 PCOS and 52 controls were sent to 10 senior Reproductive Endocrinology Infertility (REI) \& Reproductive Surgery (RS) specialists who were blinded to the research, were asked to 
analyze the HSG images and choose the most appropriate figure for each image. Experts who commented on HSG findings were not informed about the content of the study until we collected all responses.

\section{AMH assay:}

Anti-Mullerian hormone was analyzed by "Beckman Coulter Access II" enzymatic-immunoassay. In the assay, calibrators, controls and samples are incubated in microtitration wells which have been coated with anti-AMH antibody. After serial enzymatic reactions and washing steps, the degree of enzymatic turnover of the substrate is determined by dual wavelength absorbance measurement at $450 \mathrm{~nm}$ and between 600 and $630 \mathrm{~nm}$. The absorbance measured is directly proportional to the concentration of AMH in the samples. A set of AMH calibrators is used to plot a calibration curve of absorbance versus AMH concentration. The AMH concentrations in the samples Then can be calculated from this calibration curve.

\section{Statical Analysis:}

The evaluation of the uterine cavity was decided with "consensus rate". The consensus rate is described as the average of different analysts' estimates. In our study, we calculated consensus rate for normality or the uterus with the mean rating of Figure 1 (Normal uterine cavity) (n:103). As the result, it was found to be 60 percent, and the HSG images with $>6$ votes for Figure- 1 were accepted as normal uterine cavity.

Distribution of data was assessed with histograms. Depending on distribution characteristics, continuous variables were defined with mean (standard deviation) or median $\left(25^{\text {th }}\right.$ and $75^{\text {th }}$ percentiles). Categorical variables were defined as percentages. One-way analysis of variance (ANOVA), Student T test, Mann Whitney U test or chi-square test and its derivatives were used for between group comparisons. A two tailed $\mathrm{p}$ value $<0.05$ was considered as statistically significant. Spearman and Pearson correlation analysis was used to determine any correlation between variable.

\section{Ethical Considerations :}

The study was approved by local ethics committee with the approval number 2020-1/18.

\section{Accompany Centers \& Faculties:}

Barış Ata - Koç University, Bülent Yılmaz - Recep Tayyip Erdoğan University, Ercan Baştu - Acıbadem University, Hasan Onur Topçu - Medicana Hospital , Berfu Demir - Bahçeci IVF Center, Esra Bulgan Kılıçdağ - Başkent University, Gürkan Bozdă̆ - Hacettepe University, Cem Atabekoğlu - Ankara University, Bülent Haydardedeoğlu, Başkent University, Gürkan Uncu - Bursa Uludag University

\section{RESULTS}

There was no statistically significant difference in terms of age between PCSO and Control patients, respectively as $31.8 \pm 4.4$ and $31.9 \pm 5$. As expected, body mass index (BMI) was found to be higher in PCOS patient than in control $(27.2+6.2$ vs. $23.9+4.5$, p:0.03). Also, AFC and serum AMH levels were significantly higher in the PCOS group (AFC; 20 (9-20) vs. 12 (9-18) p:0.05, AMH;4.1 ng/ml (2.5-7.2) vs. $2.3 \mathrm{ng} / \mathrm{ml}(1.6-3.8), \mathrm{p}<0.01)$. There were no statistically significant differences between the PCOS patients and controls in term of serum follicle stimulating hormone (FSH) (5 IU/L (4.2-5.9) vs. 5.4 IU/L (4.4-6.2), p:0.325), Serum luteinizing hormone (LH) (3.8 IU/L (2.8-5.6) vs. $3.4 \mathrm{IU} / \mathrm{L}$ (2.6-4.1), p:0.09), free testosterone $(2.1 \mathrm{ng} / \mathrm{dl}(1.3-3.4)$ vs. $1.9 \mathrm{ng} / \mathrm{dl}$ (0.6-4.3), p:0.75), dehydroepiandrosterone sulfate (DHEASO4) (314 mcg/dl (248-408) vs. $225 \mathrm{mcg} / \mathrm{dl}(141-348)$ p:0.1), $17 \mathrm{OH}$ Progesterone $(1.64 \mathrm{ng} / \mathrm{ml}(1.1-2.2)$ vs. $0.9 \mathrm{ng} / \mathrm{ml}(0.8-2.5)$ p:0.2), except serum total testosterone levels $(0.59 \mathrm{mcg} / 1+0.19$ vs. $0.4 \mathrm{mcg} / \mathrm{l}+0.16, \mathrm{p}: 0.02)$.

HSG results are given in Table 1.

When arcuate cavity (Figure II) which is classified as an abnormality in ASRM but a variation of normal in ESGE - ESHRE is accepted as an abnormality, $45.9 \%$ and $73.1 \%$ of the uterine cavities in PCOS and control patients was reported as normal which is statistically significant (Table 1 - Analysis 1). Total uterine cavity abnormality rate (Figure II + III + IV + IV + IV) was statistically significantly higher in PCOS than in Control $(54.1 \%, 26.9 \%)$ 
When the arcuate cavity is considered normal as in the ESGE - ESHRE classification, in terms of uterine cavity abnormalities, the statistically significant difference disappears between PCOS and control patients (11.86\% versus $20.16 \%$ ) (Table 1 - Analysis 2 )

When Figure III (ESGE - ESHRE U2a / ASRM Va) and Figure IV (ESGE - ESHRE U2b / ASRM Vb) are evaluated together in the same group, there was a significant difference between PCOS and Control groups (10.57\% versus $1.2 \%)$. (Table 1 - Analysis 2 )

When these groups were evaluated separately, a statistically significant difference was found in PCOS and Control groups in Figure III (ESGE - ESHRE U2a / ASRM Va) and Figure IV (ESGE - ESHRE U2b / ASRM etc.), respectively ( $5.1 \%$ versus $0,3.4 \%$ versus $1.2 \%$ ) (Table 1 - Analysis 3 ).

When the Figure V (ESGE - ESHRE U1a / ASRM VII), which is commonly used as T shape and Figure VI (ESGE - ESHRE Uc? / ASRM Unclassified), named as Y shaped but not classified, are evaluated together in the same group, there were not statistically significant differences between the groups (21. \% versus 18.9 \%) (Table 1 - Analysis 2). When they were evaluated separately, there were no differences in terms of $\mathrm{T}$ shaped cavity between the groups $(13.8 \%$ versus $18.3 \%)$ but, the frequency of Y shaped cavity in PCOS patients was found higher than controls $(7.4 \%$ versus 0$)$.

When 6 Figures are evaluated separately, the frequency of abnormality is found higher among all groups except T shape (Figure V) in PCOS patients than in controls (Figure II; $22.1 \%$ versus $6.6 \%$, Figure III; $5.1 \%$ versus 0, Figure IV; $3.4 \%$ versus $1.2 \%$, Figure V; $7.4 \%$ versus 0) (Table 1, Analysis 3).

Uterine cavity was reported as abnormal in 28 of 51 (54.9\%) PCOS patients according to HSG results, while rest of them (23 of 51, $45.09 \%$ ) were normal.

Among PCOS patients with normal and abnormal uterine cavities, there were no statistically significant differences in terms of mean age $(32 \pm 4.5,31.6 \pm 4.4$, p:0.7), mean BMI (26.7 $\pm 6.6,27.9 \pm 5.8$, p:0.53), Ferriman Gallwey Scores (15 (12-23) vs 19 (9-21), p:0.8), AFC (20 (13-20) vs. 14 (9-20), p:0.1), serum AMH levels $(5.2 \mathrm{ng} / \mathrm{ml}(3.4-11.9)$ vs. $3.8 \mathrm{ng} / \mathrm{ml}(2.4-5.9)$, p:0.09), Serum FSH levels (5 IU/L (3.8-5.9) vs 5.2 IU/L (4.7-5.9), p:0.22), serum LH levels (3.8 IU/L (3-6.3) vs. $3.5 \mathrm{IU} / \mathrm{L}$ (2.7-5.3), p:0.6), total testosterone levels $(0.53 \mathrm{mcg} / \mathrm{L}+0.18$ vs. $0.62 \mathrm{mcg} / \mathrm{L}+0.19$, p:0.08), free testosterone levels $(2.1 \mathrm{ng} / \mathrm{dl}(1-3) \mathrm{vs.} 2.2 \mathrm{ng} / \mathrm{dl}(1.3-$ 4), p:0.44), DHEASO4 levels (322 mcg/dl (254-397) vs. $310 \mathrm{mcg} / \mathrm{dl}$ (240-418), p:0.58), 17 OH Progesterone levels $(1.3 \mathrm{ng} / \mathrm{ml}(0.9-2.1)$ vs. $1.7 \mathrm{ng} / \mathrm{dl}(1.3-2.3)$, p:0.07) between both groups.

There was no correlation between the serum AMH levels and the presence of uterine cavity abnormalities in all patients (Figure 2) and in PCOS patients as subgroup (Figure 3) (Threshold for uterine normality AMH 3.05, $50 \%$ Sensitivity 53\% Specificity, AUC 0.550 with CI (0.438-0.663) , AMH 4.05, 65\% Sensitivity \%60 Specificity, AUC 0.639 with CI (0.481-0.797), for Figure 1 and 2, respectively.

\section{Discussion:}

This study has started with this hypothesis that "the incidence of uterine abnormalities, mainly Y shaped uterine cavity, in PCOS patients is higher than normo-ovulatory patients and this can be related to maternal serum AMH levels" and ended with 2 scientifically interpretable results.

1.The rate of abnormalities in the uterine cavity was found to be higher in patients who underwent ART in PCOS patients than the patients who underwent ART because of male factor.

2. Maternal serum AMH levels do not correlate with the presence of uterine abnormalities."

Our study was based on the observation that intrauterine cavity is different than the normal structure when evaluating the cavity on HSG evaluation in PCOS patients. And the presence of scientific evidences in the literature indicating that in pregnant diagnosed with PCOS had a higher preterm delivery rate, especially those whom had higher AMH levels, emboldened us to plan this research.(8-10)

When PCOS patients are evaluated within themselves, the most frequently detected abnormality was Figure II which is classified as class VI in ASRM classification and is accepted as a variance of normal, not abnor- 
mality, in ESGE - ESHRE classification, named as arcuate. When the arcuate cavity is considered normal as in the ESGE - ESHRE classification, in terms of uterine cavity abnormalities, the statistically significant difference disappears between PCOS and control patients. (11.86 \% versus $20.16 \%$ )

PCOS is associated with a variety of complications in pregnancy, including risk of miscarriage and preterm birth. ${ }^{5-7}$ The pathophysiological mechanisms behind the increased risk of adverse pregnancy outcomes among women with polycystic ovary syndrome are not fully known. This association may be explained with the presence of uterine abnormalities.

The estimated prevalence of mullerian abnormalities is approximately $5 \%$, from mild to severe, in the general population and increase up to $13 \%$ in women with infertility. ${ }^{1}$ We were not able to find an article published among the frequency of uterine abnormalities in PCOS patients in the literature. Our research is the first research seeking the relationship between the shape of uterine cavity and PCOS. We found that the uterine cavity abnormalities in PCOS patients is $54.1 \%, 31.7 \%, 10.7 \%$ including groups (II + III + IV + V+ VI), $(\mathrm{III}+\mathrm{IV}+\mathrm{V}+\mathrm{VI}),(\mathrm{III}+\mathrm{IV})$, respectively.

The common feature of the figures II, III, IV and VI which are statistically higher in PCOS group than controls is presence of indentation of the fundal area indicating the resorption defect during the development of mullerian system.

It has been known that correct patterning and differentiation of the Mullerian Duct is dependent on a complex network of Hox and Wnt genes.(11-20) And these genes mainly regulate AMH and sex steroids both of which are main topics of PCOS under discussion. It has been shown that patients with HOXA10 mutations had uterine defects ranging from septate uterus to a didelphys uterus indicative of MD fusion defects.(21-23) In a review, it was clearly shown that intrauterine hyper exposure to testosterone influences the expressing genes.(23) There may be other mechanisms that are responsible for increased intrauterine hyper androgens linked with intrauterine AMH function. During normal pregnancy, the fetus is protected from maternal androgens by placental aromatase. It is possible, however, that placental dysfunction may expose the fetus to higher concentrations of androgens, although it has yet to be proven empirically and it was shown that Anti-mullerian hormone was able to reduce placental aromatase activity.(24,25) Also recent evidence has shown that GnRH-positive neurons express AMH receptors and that exogenous AMH potently increases $\mathrm{GnRH}$ neuron firing and $\mathrm{GnRH}$ release in murine living tissue explants.(26) Prenatal $\mathrm{AMH}$ treatment triggers the neuroendocrine disturbances of PCOS in the offspring via GnRH neuronal activation.(10)

Also, the high levels of maternal serum AMH levels during pregnancy in PCOS patients may be a cause of formation of PCOS in female fetus in utero. Since AMH is secreted from granulosa cells in females, AMH secretion is not expected until the granulosa cells are activated. Previous studies reported that the expression of AMH in the ovary is switched on soon after birth and concluded that there is no detectable ovarian production during normal fetal.(27-30) In spite of this, many authors reported the expression patterns of AMH with in human fetal ovarian specimens, in the end of the gestation, in the granulosa cells of preantral follicles.(31-33) The different structure and physiology of granulosa cells in PCOS patients may also be in the intrauterine period and cord blood AMH levels may be higher in the female fetuses, who will later develop PCOS. Tata B et al. reported that AMH levels are higher in pregnant PCOS subjects than in pregnant control women and suggested that elevated prenatal anti-mullerian hormone reprograms the fetus and induces polycystic ovary.(33) However, umbilical cord blood AMH and sex steroid levels of later developing PCOS patients in intrauterine period is not known.

The only study in the literature thoroughly researching this topic is by Hart R et al., in which maternal blood samples were collected at 18 and 34 weeks and umbilical cord blood was collected at 870 singleton deliveries. The cohort included 1800 adolescents aged 16 to 18 years. The cord blood of adolescent girl was available for 77 of the 244 girls consented to research. No statistically significant associations between maternal and cord androgens and AMH in adolescents were found.(34)

In the literature, there is no study investigating the relationship between maternal AMH levels and the 
frequency of uterine abnormality. In our study, no difference was found between maternal serum AMH levels and the presence of uterine abnormalities in all study groups and PCOS subgroup analysis. We can comment that maternal serum AMH levels do not have any effect on the presence of uterine abnormalities."

In our study, the rate of $\mathrm{T}$ shaped uterine abnormality which is figured as $\mathrm{V}$ was not found to be statistically different in PCOS group than in controls. However, the rates of figures II, III, and IV were much higher in PCOS than in controls. T shape uterus is not a resorption abnormality and the first $\mathrm{T}$ shaped uterus case was reported after DES exposure. In the presence of the $\mathrm{T}$ shape uterus, the fundus of the uterine cavity is completely normal. The $\mathrm{T}$ shaped uterus is different from the other anomalies by the mechanism of formation. Mechanism of formation of $\mathrm{T}$ shaped is related to the hyperplasia of the mesenchymal tissue connected to WNT genes driving by DES and other factors.(35) In our study, the high frequency of T-shaped uterine cavity and no differences between PCOS and control group can be explained by the fact that the diagnostic criteria of the T-shaped uterus is not fully defined. We report and suggest that the T shape cavity abnormality is not related to PCOS disease.

There is no place of $\mathrm{Y}$ shaped cavity in the classifications in both classifications.(2) However, besides the defined cavity abnormalities in the classifications, there is a common observation by the REI specialists \& REI Surgeons who are focused on this topic, called Y and I shaped cavities which is under discussion and accepted as normal today. The most important study in this topic is Y shaped uterus defined and emphasized on clinical importance reported by Di Spiezio Sardo A.(36) In this study, although the Y shape is not classified as an abnormality other than the T shape, in the annotated figure of the surgical technique, it is clearly understood that the cases are Y shaped and surgical treatment is performed with this principle. And in this study, it is reported a net increase of uterine volume was found, as measured by hysteroscopy and three-dimensional transvaginal ultrasound, uterine morphology improved in all patients, clinical pregnancy rate was $57 \%$ and term delivery rate $65 \%$.

In a review published by Alonso L., it was stated that the morphologic conditions like T, Y and I shaped uterine abnormalities must be investigated as a structural and functional disorder.(37)

Y shaped cavity which was figured as 6 in our study, although not defined as an abnormality in the classifications, exists and was higher in the PCOS patients as $7.4 \%$ than in controls. Its clinical significance is not fully known. It needs further research.

\section{Conclusion:}

We found that the frequency of uterine abnormality is more common in PCOS patients than the normal population and this is not correlated with maternal serum AMH levels.

Considering that PCOS is a transgenerational and transmissible disease, high frequency of uterine cavity abnormalities in PCOS patients can be attributed to increased, either direct effect of cord blood AMH levels to uterine development via WNT genes or indirect effect of AMH via increasing intrauterine GnRh Pulsatility - LH levels or reducing placental aromatase enzyme which is blocking maternal androgens, intrauterine androgens and downregulation of HOXA genes. (Figure 4)

Longitudinal studies are needed to investigate the relationship between umbilical cord AMH, androgens and other sex steroids levels, shape of uterine cavity and pregnancy complications.

\section{Acknowledgements:}

We thank all seniors for analyzing HSG images of the patients. (Barış Ata - Koç University, Bülent Yılmaz - Recep Tayyip Erdoğan University, Ercan Baştu - Acıbadem University, Hasan Onur Topçu - Medicana Hospital, Berfu Demir - Bahçeci IVF Center, Esra Bulgan Kılıçdağ - Başkent University, Gürkan Bozdağ - Hacettepe University, Cem Atabekoğlu - Ankara University, Bülent Haydardedeoğlu - Başkent University, Mehtap Polat - Anatolia IVF Center)

\section{Conflict of Interests:}


All authors declare that, there is no conflict of interest.

\section{Contribution to Authorship:}

Uncu G. designed, drafted and revised the study. Albayrak O. and Orhaner A. collected the data and provide HSG images to the seniors. Aslan K. analyzed the data and interpreted the results. Kasapoglu I. participated in interpreting the data and revising the study.

\section{Ethical Approval:}

The study was approved by Bursa Uludag University Ethic committee with the approval number 2020-1/18.

\section{Funding:}

There is no funding

\section{References}

1. Chan YY, Jayaprakasan K, Zamora J, Thornton JG, Raine-Fenning N CA. The Prevalence of Congenital Uterine Anomalies in Unselected and High-Risk Populations: A Systematic Review - PubMed. Hum Reprod Update. 2011. p. 17(6):761-771.

2. Grimbizis GF, Gordts S, Di Spiezio Sardo A, Brucker S, De Angelis C, Gergolet M, et al. The ESHREESGE consensus on the classification of female genital tract congenital anomalies. Gynecol Surg. 2013 Aug;10(3):199-212.

3. Buttram VC, Gomel V, Siegler A, DeCherney A, Gibbons W, March C. The American Fertility Society classifications of adnexal adhesions, distal tubal occlusion, tubal occlusion secondary to tubal ligation, tubal pregnancies, Mullerian anomalies and intrauterine adhesions. Fertil Steril. 1988;49(6):944-55.

4. Bozdag G, Mumusoglu S, Zengin D, Karabulut E YB. The Prevalence and Phenotypic Features of Polycystic Ovary Syndrome: A Systematic Review and Meta-Analysis - PubMed. Hum Reprod. 2016;31(12):28412855. 2016. p. 31(12):2841-2855.

5. Roos N, Kieler H, Sahlin L, Ekman-Ordeberg G, Falconer H, Stephansson O. Risk of adverse pregnancy outcomes in women with polycystic ovary syndrome: Population based cohort study. BMJ. 2011 Oct $22 ; 343(7828)$.

6. Wang T, Fu H, Chen L, Xu Y. Pregnancy complications among women with polycystic ovary syndrome in China: A Meta-analysis. J Cent South Univ (Medical Sci. 2017 Nov 1;42(11):1300-10.

7. Palomba S, De Wilde MA, Falbo A, Koster MPH, La Sala GB, Fauser BCJM. Pregnancy complications in women with polycystic ovary syndrome. Hum Reprod Update. 2015;21(5):575-92.

8. Hu KL, Liu FT, Xu H, Li R, Qiao J. High antimüllerian hormone levels are associated with preterm delivery in patients with polycystic ovary syndrome. Fertil Steril. 2020 Feb 1;113(2):444-452.e1.

9. Hsu JY, James KE, Bormann CL, Donahoe PK, Pépin D, Sabatini ME. Müllerian-inhibiting substance/anti-Müllerian hormone as a predictor of preterm birth in polycystic ovary syndrome. J Clin Endocrinol Metab. 2018;103(11):4187-96.

10. Valdimarsdottir R, Valgeirsdottir H, Wikström AK, Kallak TK, Elenis E, Axelsson O, et al. Pregnancy and neonatal complications in women with polycystic ovary syndrome in relation to second-trimester antiMüllerian hormone levels. Reprod Biomed Online. 2019 Jul 1;39(1):141-8.

11. Taylor HS, Vanden Heuvel GB, Igarashi P. A Conserved Hox Axis in the Mouse and Human Female Reproductive System: Late Establishment and Persistent Adult Expression of the Hoxa Cluster Genes. Biol Reprod. 1997 Dec 1;57(6):1338-45.

12. Lewis EB. A gene complex controlling segmentation in Drosophila. Vol. 276, Nature. Nature; 1978. p. $565-70$. 
13. McGinnis W, Garber RL, Wirz J, Kuroiwa A, Gehring WJ. A homologous protein-coding sequence in drosophila homeotic genes and its conservation in other metazoans. Cell. 1984;37(2):403-8.

14. McGinnis W, Levine MS, Hafen E, Kuroiwa A, Gehring WJ. A conserved DNA sequence in homoeotic genes of the Drosophila Antennapedia and bithorax complexes. Nature. 1984;308(5958):428-33.

15. McGinnis W, Krumlauf R. Homeobox genes and axial patterning. Vol. 68, Cell. Cell; 1992. p. 283-302.

16. Mullen RD, Behringer RR. Molecular genetics of Müllerian duct formation, regression and differentiation. Sex Dev. 2014 Sep 1;8(5):281-96.

17. Krumlauf R. Hox genes in vertebrate development. Vol. 78, Cell. Cell; 1994. p. 191-201.

18. Block K, Kardana A, Igarashi P, Taylor HS. In utero diethylstilbestrol (DES) exposure alters Hox gene expression in the developing mullerian system. FASEB J. 2000 Jun;14(9):1101-8.

19. Massé J, Watrin T, Laurent A, Deschamps S, Guerrier D, Pellerin I. The developing female genital tract: From genetics to epigenetics. Vol. 53, International Journal of Developmental Biology. Int J Dev Biol; 2009. p. $411-24$.

20. Benson G V., Lim H, Paria BC, Satokata I, Dey SK, Maas RL. Mechanisms of reduced fertility in Hoxa-10 mutant mice: Uterine homeosis and loss of maternal Hoxa-10 expression. Development. 1996;122(9):2687-96.

21. Cheng Z, Zhu Y, Su D et al. A Novel Mutation of HOXA10 in a Chinese Woman With a Mullerian Duct Anomaly - PubMed. Hum Reprod. 2011. p. 26(11):3197-3201.

22. Filippou P HR. Is Foetal Hyperexposure to Androgens a Cause of PCOS? - PubMed. Hum Reprod Update. . 2017. p. 23(4):421-432.

23. Piltonen TT, Giacobini P, Edvinsson A, Hustad S, Lager S, Morin-Papunen L, et al. Circulating antimüllerian hormone and steroid hormone levels remain high in pregnant women with polycystic ovary syndrome at term. Fertil Steril. 2019 Mar 1;111(3):588-596.e1.

24. Maliqueo M, Lara HE, Sánchez F, Echiburú B, Crisosto N, Sir-Petermann T. Placental steroidogenesis in pregnant women with polycystic ovary syndrome. Eur J Obstet Gynecol Reprod Biol. 2013;166(2):151-5.

25. Cimino I, Casoni F, Liu X, Messina A, Parkash J, Jamin SP, et al. Novel role for anti-Müllerian hormone in the regulation of GnRH neuron excitability and hormone secretion. Nat Commun. 2016 Jan 12;7.

26. Tadaion Far F, Jahanian Sadatmahalleh S, Ziaei S, Kazemnejad A. Comparison of the umbilical cord Blood's anti-Mullerian hormone level in the newborns of mothers with polycystic ovary syndrome (PCOS) and healthy mothers. J Ovarian Res. 2019 Nov 17;12(1).

27. Hirobe S, He WW, Lee MM, Donahoe PK. Mullerian inhibiting substance messenger ribonucleic acid expression in granulosa and sertoli cells coincides with their mitotic activity. Endocrinology. 1992;131(2):85462.

28. Guibourdenche J, Lucidarme N, Chevenne D, Rigal O, Nicolas M, Luton D, et al. Anti-Müllerian hormone levels in serum from human foetuses and children: Pattern and clinical interest. In: Molecular and Cellular Endocrinology. Elsevier Ireland Ltd; 2003. p. 55-63.

29. Lee MM, Donahoe PK, Hasegawa T, Silverman B, Crist GB, Best S, et al. Mullerian inhibiting substance in humans: normal levels from infancy to adulthood. J Clin Endocrinol Metab. 1996 Feb;81(2):571-6.

30. Rajpert-De Meyts E, Jørgensen N, Græm N, Müller J, Cate RL, Skakkebæk NE. Expression of AntiMüllerian Hormone during Normal and Pathological Gonadal Development: Association with Differentiation of Sertoli and Granulosa Cells 1. J Clin Endocrinol Metab. 1999 Oct;84(10):3836-44.

31. Kuiri-Hänninen T, Kallio S, Seuri R, Tyrväinen E, Liakka A, Tapanainen J, et al. Postnatal developmental changes in the pituitary-ovarian axis in preterm and term infant girls. J Clin Endocrinol Metab. 2011 
Nov;96(11):3432-9.

32. Hagen CP, Aksglaede L, Sørensen K, Main KM, Boas M, Cleemann L, et al. Serum levels of anti-Müllerian hormone as a marker of ovarian function in 926 healthy females from birth to adulthood and in 172 turner syndrome patients. J Clin Endocrinol Metab. 2010;95(11):5003-10.

33. Tata B, Mimouni NEH, Barbotin AL, Malone SA, Loyens A, Pigny P, et al. Elevated prenatal antiMüllerian hormone reprograms the fetus and induces polycystic ovary syndrome in adulthood. Nat Med. 2018 Jun $1 ; 24(6): 834-46$.

34. Hart R, Sloboda DM, Doherty DA, Norman RJ, Atkinson HC, Newnham JP, et al. Circulating maternal testosterone concentrations at 18 weeks of gestation predict circulating levels of antimüllerian hormone in adolescence: A prospective cohort study. Fertil Steril. 2010 Sep;94(4):1544-7.

35. Franco HL, Dai D, Lee KY, Rubel CA, Roop D, Boerboom D, et al. WNT4 is a key regulator of normal postnatal uterine development and progesterone signaling during embryo implantation and decidualization in the mouse. FASEB J. 2011 Apr;25(4):1176-87.

36. Di Spiezio Sardo A, Florio P, Nazzaro G, Spinelli M, Paladini D, Di Carlo C, et al. Hysteroscopic outpatient metroplasty to expand dysmorphic uteri (HOME-DU technique): A pilot study. Reprod Biomed Online. 2015 Feb 1;30(2):166-74.

37. Alonso L, Haimovich S, Di Spiezio Sardo A, Carugno J. Dysmorphic Uterus: Do We Need a T-Y-I Subclassification? Vol. 27, Journal of Minimally Invasive Gynecology. Elsevier B.V.; 2020. p. 4-6.

\begin{tabular}{|c|c|c|c|c|c|c|c|c|}
\hline & NORMAL & $\begin{array}{l}\text { ESGE / } \\
\text { ESHRE } \\
\text {-Normal } \\
\text { ASRM VI }\end{array}$ & $\begin{array}{l}\text { ESGE / } \\
\text { ESHRE } \\
\text {-Normal } \\
\text { ASRM VI }\end{array}$ & $\begin{array}{l}\text { ESGE / } \\
\text { ESHRE - } \\
\text { U2a ASRM } \\
\text { - Va }\end{array}$ & $\begin{array}{l}\text { ESGE/ } \\
\text { ESHRE - } \\
\text { U2b ASRM } \\
- \text { Vb }\end{array}$ & $\begin{array}{l}\text { ESGE / } \\
\text { ESHRE - } \\
\text { U1a ASRM } \\
\text { - VII }\end{array}$ & $\begin{array}{l}\text { ESGE / } \\
\text { ESHRE - } \\
\text { Uc? ASRM } \\
- \\
\text { Unclassifed }\end{array}$ & $\begin{array}{l}\text { ESGE } \\
\text { ESHRE } \\
\text { Uc? AS } \\
- \\
\text { Unclass }\end{array}$ \\
\hline $\begin{array}{l}\text { TYPES } \\
\text { OF } \\
\text { UTER- } \\
\text { INE } \\
\text { CAVITY }\end{array}$ & Figure I & Figure II & Figure II & Figure III & Figure IV & Figure V & Figure VI & Figure \\
\hline ANALYSIS & ANALYSIS & ANALYSIS & ANALYSIS & ANALYSIS & ANALYSIS & ANALYSIS & ANALYSIS & \\
\hline 1 & 1 & 1 & 1 & 1 & 1 & 1 & 1 & \\
\hline & $\begin{array}{l}(\mathrm{n} / \mathrm{)} \\
\%\end{array}$ & $\begin{array}{l}\mathbf{I I}+ \\
\mathbf{I I I} \\
+\mathbf{I V}+ \\
\mathbf{V}+\mathbf{V I} \\
(\mathrm{n} /) \\
\%\end{array}$ & $\begin{array}{l}\mathbf{I I}+ \\
\mathbf{I I I} \\
+\mathbf{I V}+ \\
\mathbf{V}+\mathbf{V I} \\
(\mathrm{n} /) \\
\%\end{array}$ & $\begin{array}{l}\mathbf{I I}+ \\
\mathbf{I I I} \\
+\mathbf{I V}+ \\
\mathbf{V}+\mathbf{V I} \\
(\mathrm{n} /) \\
\%\end{array}$ & $\begin{array}{l}\mathbf{I I}+ \\
\mathbf{I I I} \\
+\mathbf{I V}+ \\
\mathbf{V}+\mathbf{V I} \\
(\mathrm{n} /) \\
\%\end{array}$ & $\begin{array}{l}\mathbf{I I}+ \\
\mathbf{I I I} \\
+\mathbf{I V}+ \\
\mathbf{V}+\mathbf{V I} \\
(\mathrm{n} /) \\
\%\end{array}$ & $\begin{array}{l}\mathbf{I I}+ \\
\mathbf{I I I} \\
+\mathbf{I V}+ \\
\mathbf{V}+\mathbf{V I} \\
(\mathrm{n} /) \\
\%\end{array}$ & $\begin{array}{l}\mathbf{I I}+ \\
\mathbf{I I I} \\
+\mathbf{I V}+ \\
\mathbf{V}+\mathbf{V} \\
(\mathrm{n} /) \\
\%\end{array}$ \\
\hline PCOS & $(23 / 51)$ & $(28 / 51)$ & $(28 / 51)$ & $(28 / 51)$ & $(28 / 51)$ & $(28 / 51)$ & $(28 / 51)$ & $(28 / 51)$ \\
\hline CONTROL & $\begin{array}{l}45.9 \\
(38 / 52)\end{array}$ & $\begin{array}{l}54.1 \\
(14 / 52)\end{array}$ & $\begin{array}{l}54.1 \\
(14 / 52)\end{array}$ & $\begin{array}{l}54.1 \\
(14 / 52)\end{array}$ & $\begin{array}{l}54.1 \\
(14 / 52)\end{array}$ & $\begin{array}{l}54.1 \\
(14 / 52)\end{array}$ & $\begin{array}{l}54.1 \\
(14 / 52)\end{array}$ & $\begin{array}{l}54.1 \\
(14 / 52)\end{array}$ \\
\hline & 73.1 & 26.9 & 26.9 & 26.9 & 26.9 & 26.9 & 26.9 & 26.9 \\
\hline $\mathrm{P}<$ & $\mathrm{P}<$ & $\mathrm{P}<$ & $\mathrm{P}<$ & $\mathrm{P}<$ & $\mathrm{P}<$ & $\mathrm{P}<$ & $\mathrm{P}<$ & $\mathrm{P}<$ \\
\hline 0.05 & 0.05 & 0.05 & 0.05 & 0.05 & 0.05 & 0.05 & 0.05 & 0.05 \\
\hline ANALYSIS & ANALYSIS & ANALYSIS & ANALYSIS & ANALYSIS & ANALYSIS & ANALYSIS & ANALYSIS & \\
\hline 2 & $\mathbf{2}$ & $\mathbf{2}$ & $\begin{array}{l}2 \\
\text { III } \\
+ \text { IV }\end{array}$ & $\begin{array}{l}2 \\
\text { III } \\
+ \text { IV }\end{array}$ & $\begin{array}{l}2 \\
\text { III } \\
+ \text { IV }\end{array}$ & $\begin{array}{l}\mathbf{2} \\
\mathbf{V}\end{array}+\mathbf{V I}$ & $\begin{array}{l}\mathbf{2} \\
\mathbf{V}+\mathbf{V I}\end{array}$ & \\
\hline
\end{tabular}




\begin{tabular}{|c|c|c|c|c|c|c|c|c|}
\hline & NORMAL & $\begin{array}{l}\text { ESGE / } \\
\text { ESHRE } \\
\text {-Normal } \\
\text { ASRM VI }\end{array}$ & $\begin{array}{l}\text { ESGE / } \\
\text { ESHRE } \\
\text {-Normal } \\
\text { ASRM VI }\end{array}$ & $\begin{array}{l}\text { ESGE / } \\
\text { ESHRE - } \\
\text { U2a ASRM } \\
\text { - Va }\end{array}$ & $\begin{array}{l}\text { ESGE/ } \\
\text { ESHRE - } \\
\text { U2b ASRM } \\
- \text { Vb }\end{array}$ & $\begin{array}{l}\text { ESGE / } \\
\text { ESHRE - } \\
\text { U1a ASRM } \\
\text { - VII }\end{array}$ & $\begin{array}{l}\text { ESGE / } \\
\text { ESHRE - } \\
\text { Uc? ASRM } \\
- \\
\text { Unclassifed }\end{array}$ & $\begin{array}{l}\text { ESGE } \\
\text { ESHRI } \\
\text { Uc? A } \\
- \\
\text { Unclas }\end{array}$ \\
\hline & $\begin{array}{l}(\mathrm{n} / \mathrm{)} \\
\%\end{array}$ & $\begin{array}{l}(\mathrm{n} /) \\
\%\end{array}$ & $\begin{array}{l}(\mathrm{n} /) \\
\%\end{array}$ & $(\mathrm{n} / \mathrm{)})$ & $\begin{array}{l}(\mathrm{n} /) \\
\%\end{array}$ & $\begin{array}{l}(\mathrm{n} /) \\
\%\end{array}$ & $\begin{array}{l}(\mathrm{n} / \mathrm{)}) \\
\%\end{array}$ & \\
\hline \multirow[t]{2}{*}{ PCOS } & $(35 / 51)$ & $(35 / 51)$ & $(5 / 51)$ & $(5 / 51)$ & $(5 / 51)$ & $(11 / 51)$ & $(11 / 51)$ & \\
\hline & 68.8 & 68.8 & 10.57 & 10.57 & 10.57 & 21.2 & 21.2 & \\
\hline \multirow[t]{2}{*}{ CONTORL } & $(41 / 52)$ & $(41 / 52)$ & $(1 / 52)$ & $(1 / 52)$ & $(1 / 52)$ & $(10 / 52)$ & $(10 / 52)$ & \\
\hline & 79.84 & 79.84 & 1.21 & 1.21 & 1.21 & 18.9 & 18.9 & \\
\hline $\mathrm{P}<$ & & & $\mathrm{P}<$ & $\mathrm{P}<$ & $\mathrm{P}<$ & & & \\
\hline 0.05 & & & 0.05 & 0.05 & 0.05 & & & \\
\hline ANALYSIS & ANALYSIS & ANALYSIS & ANALYSIS & ANALYSIS & ANALYSIS & ANALYSIS & ANALYSIS & \\
\hline \multirow[t]{2}{*}{3} & 3 & 3 & 3 & 3 & 3 & 3 & 3 & \\
\hline & $\begin{array}{l}\mathbf{I} \\
(\mathrm{n} /) \\
\%\end{array}$ & $\begin{array}{l}\text { II } \\
(\mathrm{n} /) \\
\%\end{array}$ & $\begin{array}{l}\text { II } \\
(\mathrm{n} /) \\
\%\end{array}$ & $\begin{array}{l}\text { III } \\
(\mathrm{n} /) \\
\%\end{array}$ & $\begin{array}{l}\mathbf{I V} \\
(\mathrm{n} /) \\
\%\end{array}$ & $\begin{array}{l}\mathbf{V} \\
(\mathrm{n} /) \\
\%\end{array}$ & $\begin{array}{l}\text { VI } \\
(\mathrm{n} /) \\
\%\end{array}$ & $\begin{array}{l}\text { VI } \\
(\mathrm{n} /) \\
\%\end{array}$ \\
\hline \multirow[t]{2}{*}{ PCOS } & $(23 / 51)$ & $(12 / 51)$ & $(12 / 51)$ & $(2 / 51)$ & $(3 / 51)$ & $(7 / 51)$ & $(4 / 51)$ & $(4 / 51)$ \\
\hline & 45.9 & 22.18 & 22.18 & 5.1 & 5.47 & 13.8 & 7.47 & 7.47 \\
\hline \multirow[t]{2}{*}{ CONTORL } & $(38 / 52)$ & $(3 / 52)$ & $(3 / 52)$ & 0 & $(1 / 52)$ & $(10 / 52)$ & 0 & 0 \\
\hline & 73.1 & 6.6 & 6.6 & & 1.2 & 18.3 & & \\
\hline $\mathrm{P}<$ & $\mathrm{P}<$ & $\mathrm{P}<$ & $\mathrm{P}<$ & $\mathrm{P}<$ & $\mathrm{P}<$ & & $\mathrm{P}<$ & $\mathrm{P}<$ \\
\hline 0.05 & 0.05 & 0.05 & 0.05 & 0.05 & 0.05 & & 0.05 & 0.05 \\
\hline
\end{tabular}

Table - 1: HSG Results

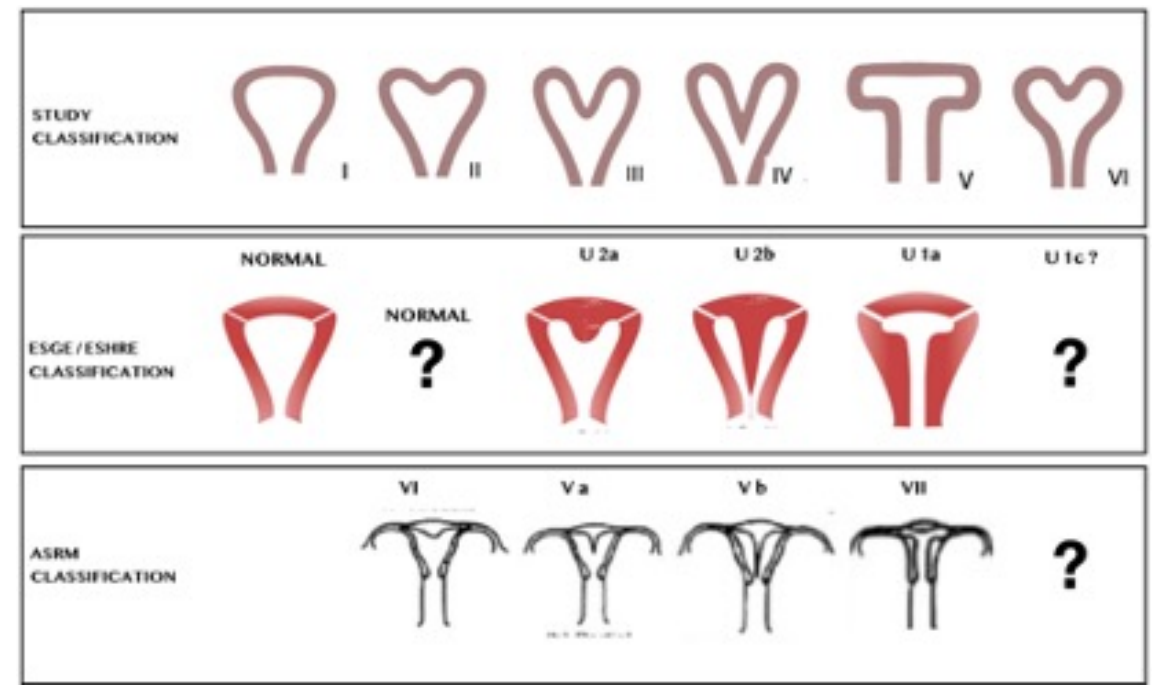



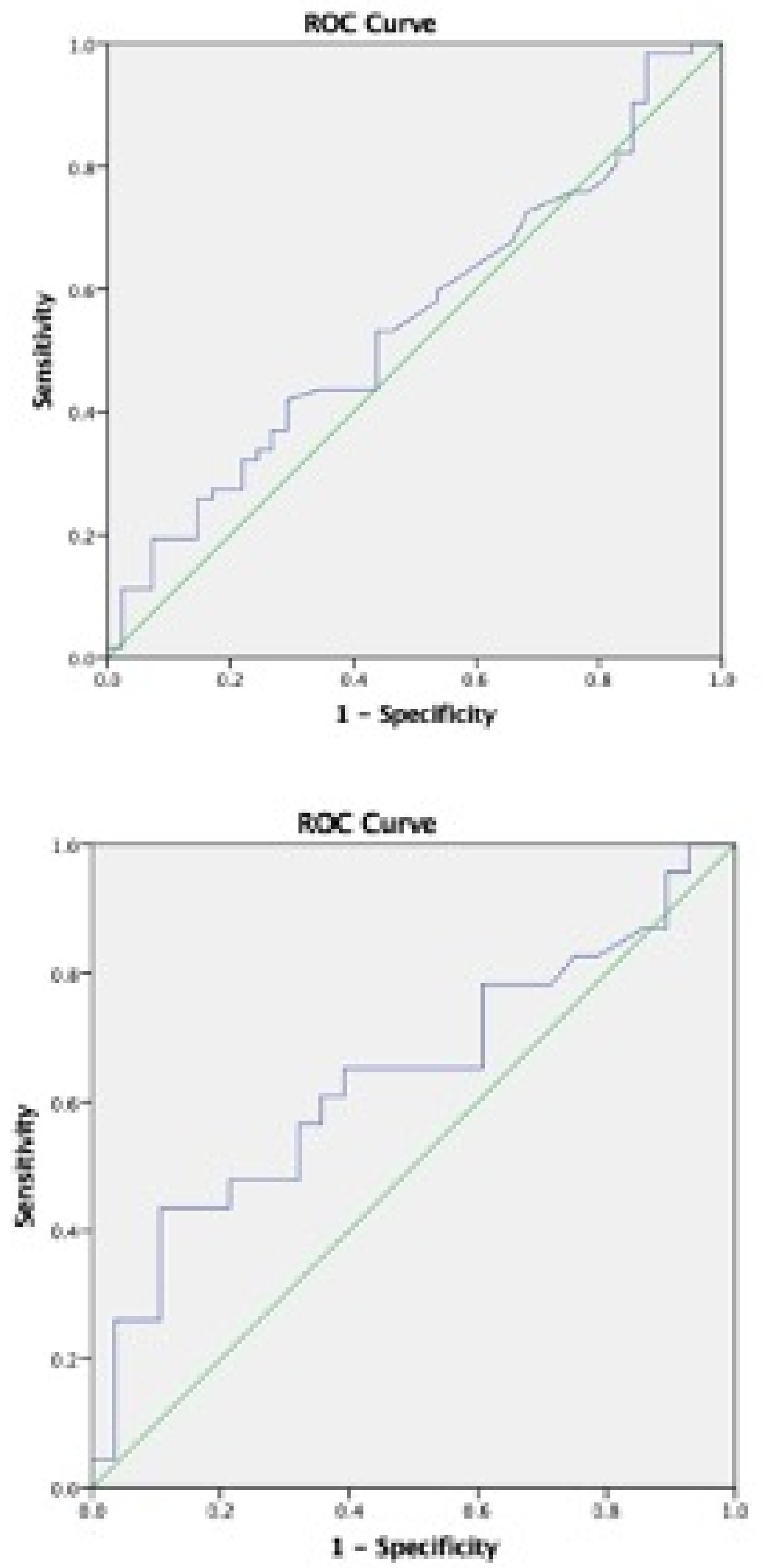


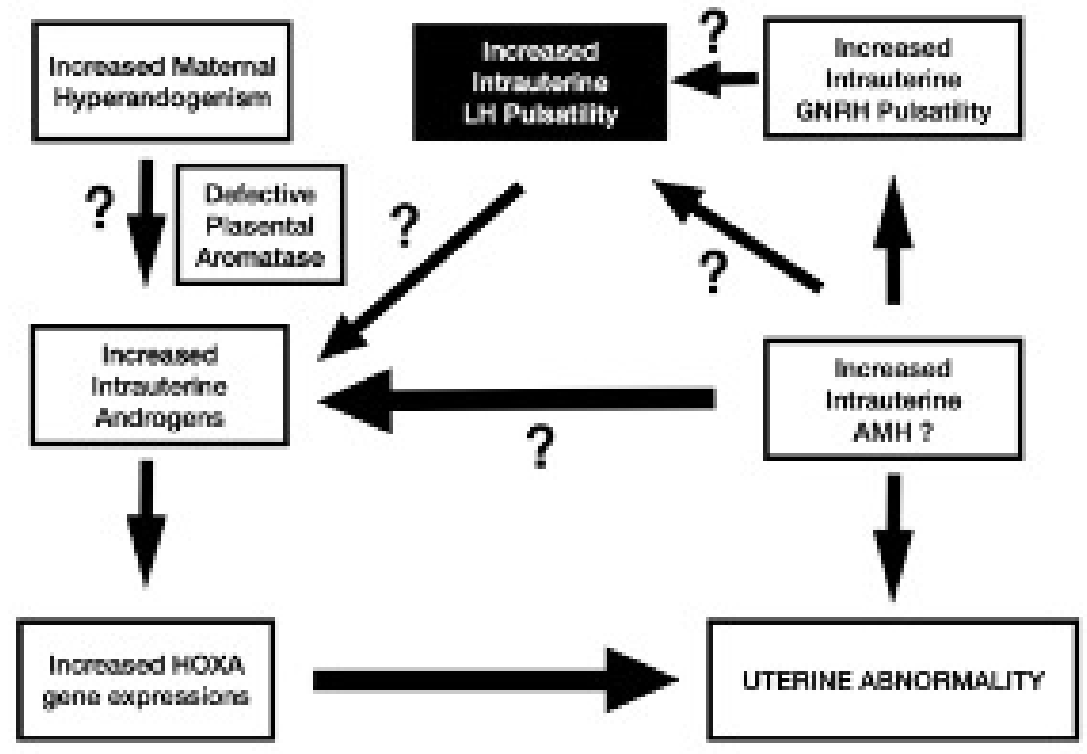

